\title{
Role of the dorsal anterior cingulate cortex in obsessive-compulsive disorder: converging evidence from cognitive neuroscience and psychiatric neurosurgery
}

\author{
Robert A. McGovern, MD, and Sameer A. Sheth, MD, PhD \\ Department of Neurological Surgery, The Neurological Institute, Columbia University Medical Center, New York, New York
}

OBJECTIVE Advances in understanding the neurobiological basis of psychiatric disorders will improve the ability to refine neuromodulatory procedures for treatment-refractory patients. One of the core dysfunctions in obsessive-compulsive disorder (OCD) is a deficit in cognitive control, especially involving the dorsal anterior cingulate cortex (dACC). The authors' aim was to derive a neurobiological understanding of the successful treatment of refractory OCD with psychiatric neurosurgical procedures targeting the dACC.

METHODS First, the authors systematically conducted a review of the literature on the role of the dACC in OCD by using the search terms "obsessive compulsive disorder" and "anterior cingulate." The neuroscience literature on cognitive control mechanisms in the $\mathrm{AACC}$ was then combined with the literature on psychiatric neurosurgical procedures targeting the $d A C C$ for the treatment of refractory OCD.

RESULTS The authors reviewed 89 studies covering topics that included structural and functional neuroimaging and electrophysiology. The majority of resting-state functional neuroimaging studies demonstrated dACC hyperactivity in patients with $O C D$ relative to that in controls, while task-based studies were more variable. Electrophysiological studies showed altered dACC-related biomarkers of cognitive control, such as error-related negativity in OCD patients. These studies were combined with the cognitive control neurophysiology literature, including the recently elaborated expected value of control theory of $\mathrm{dACC}$ function. The authors suggest that a central feature of OCD pathophysiology involves the generation of mis-specified cognitive control signals by the $\mathrm{dACC}$, and they elaborate on this theory and provide suggestions for further study.

CONCLUSIONS Although abnormalities in brain structure and function in $O C D$ are distributed across a wide network, the AACC plays a central role. The authors propose a theory of cognitive control dysfunction in OCD that attempts to explain the therapeutic efficacy of dACC neuromodulation. This theoretical framework should help to guide further research into targeted treatments of $\mathrm{OCD}$ and other disorders of cognitive control.

http://thejns.org/doi/abs/10.3171/2016.1.JNS15601

KEY WORDS dorsal anterior cingulate cortex; cognitive control; obsessive-compulsive disorder; psychiatric neurosurgery; expected value of control; cingulotomy; functional neurosurgery

$\mathrm{N}$ EUROMODULATORY procedures are being recognized as increasingly valuable options for patients with treatment-refractory psychiatric disorders. As our understanding and theoretical modeling of the neurocircuitry underlying these disorders improve, we can expect the efficacy and specificity of these therapies to improve in parallel. The process of model refinement and treatment targeting is often iterative, with advances in one realm driving progress in the other in reciprocal fashion. In this paper, we highlight an example of this process.

We focus on one of the most common psychiatric disorders treated with neuromodulatory approaches, obsessive-compulsive disorder (OCD), which is characterized by both obsessions (persistent, intrusive, often irrational

ABBREVIATIONS ALIC = anterior limb of internal capsule; $\mathrm{dACC}=$ dorsal anterior cingulate cortex; CS = conditioned stimulus; CSTC = cortico-striato-thalamo-cortical; $\mathrm{DBS}=$ deep brain stimulation; dIPFC = dorsolateral prefrontal cortex; EEG = electroencephalography; ERN = error-related negativity; ERP = exposure-response prevention; $\mathrm{EVC}=$ expected value of control; fMRI = functional MRI; IPFC = lateral prefrontal cortex; $\mathrm{NIMH}=\mathrm{National}$ Institute of Mental Health; OCD = obsessive-compulsive disorder; $\mathrm{OFC}=$ orbitofrontal cortex; RCT = randomized controlled trial; RDoC = Research Domain Criteria; US = unconditioned stimulus; VC = ventral ALIC; vmPFC = ventro-mesial prefrontal cortex; VS = ventral striatum; YBOCS = Yale-Brown Obsessive-Compulsive Scale.

SUBMITTED March 16, 2015. ACCEPTED January 7, 2016.

INCLUDE WHEN CITING Published online April 1, 2016; DOI: 10.3171/2016.1.JNS15601. 
and uncontrollable thoughts, images, or urges) and compulsions (repetitive, often ritualistic behaviors or thoughts performed to reduce anxiety or distress $)^{107}$ and has a relatively high lifetime prevalence of $2 \%-3 \% .{ }^{138}$ Almost twothirds of patients report severe impairment at home and work, as well as in interpersonal relationships and social life. ${ }^{138}$ Both pharmacotherapy (serotonin reuptake inhibitors and other drug classes) and cognitive-behavioral therapy (especially exposure-response prevention [ERP]) have proved efficacious in treating OCD, with approximately $50 \%-70 \%$ of patients demonstrating improvement after completing a treatment course. ${ }^{39}$ However, patients are frequently left with residual symptoms, and maintaining treatment efficacy remains a significant problem. ${ }^{39} \mathrm{In}$ addition, $10 \%-15 \%$ of severely affected patients remain refractory to long-term standard therapies ${ }^{44,150}$ and therefore may be candidates for neurosurgical procedures, including deep brain stimulation (DBS) ${ }^{103,160}$ and stereotactic lesions. ${ }^{19,119}$

Several brain regions have been implicated in the pathophysiology of OCD. These include cortical regions such as the orbitofrontal cortex (OFC), ventro-mesial prefrontal cortex (vmPFC), and dorsal anterior cingulate cortex (dACC), as well as deep nuclei such as the dorsal and ventral striatum (VS), amygdala, pallidum, and thalamus (for a review ${ }^{106,120}$. Here, we focus on the role of the dACC given the efficacy of stereotactic lesions in this region (dorsal anterior cingulotomy) in the treatment of refractory OCD. ${ }^{147}$

The National Institute of Mental Health (NIMH) recently proposed a new strategy for classifying disorders of mental health based on neurobiological measures, termed the Research Domain Criteria (RDoC) project. ${ }^{66}$ A phenomenological diagnosis such as OCD would thus be reclassified according to the dysfunction of fundamental constituent aspects of behavior and circuitry. Some of the key aspects of dysfunction in OCD include performance monitoring, response inhibition, and goal selection, all of which are classified under the RDoC construct of "Cognitive Control" (which is contained within the larger domain of "Cognitive Systems"). "Cognitive (or effortful) control" refers to the ability to focus on relevant environmental stimuli while ignoring irrelevant ones, inhibit responses influenced by distracting elements, select appropriate responses, monitor the outcome of those responses, and adjust behavior as needed in the face of changing situations. Several studies have identified deficits in cognitive control in patients with OCD. ${ }^{8,11,89,134}$

The aim of the present study was to improve our understanding of the neurobiological basis of neurosurgical procedures targeting the dACC for OCD. We begin with a systematic review of studies involving any method of studying dACC function (imaging, electrophysiological, surgical) in adults with OCD. We discuss our current understanding of the role of the AACC in cognitive control, as established by the neuroscientific literature using neuroimaging and electrophysiology in animals and humans. We propose, based on this literature, that an important component of OCD pathology derives from aberrant cognitive control signals generated by the dACC. We then synthesize this proposal, which was derived from the cog- nitive neuroscience literature, with the literature on psychiatric neurosurgical procedures targeting the dACC for the treatment of refractory OCD. These 2 fields have little mutual interest historically, but their intersection in dACC physiology and pathophysiology provides an opportunity for cross-fertilization. Finally, we discuss the implications of our theory and provide suggestions for future research to explore it further. In doing so, we hope to advance the development of increasingly rationally designed and effective targeted treatments for OCD and other psychiatric disorders.

\section{Methods}

To identify the role of the AACC in OCD, we systematically reviewed the English-language literature according to the PRISMA systematic review checklist ${ }^{108}$ (Fig. 1). We used the PubMed search terms "obsessive compulsive disorder" and "anterior cingulate" for the period from January 1,2000, to September 1, 2014, limiting the search to English-language journal articles involving humans. This query resulted in 224 publications. We included only those studies with adults who had a diagnosis of OCD, as the treatment of pediatric or subclinical forms of OCD are outside the scope of this review. We included all publications involving neuroimaging except for the MR spectroscopy studies, as the neurochemical profile of OCD is also outside the scope of this review. While we used reviews to identify issues related to OCD and non-dACC regions, these were not included in the list of publications for review. After excluding the above studies, 85 publications remained in our literature search. Most of these studies involved structural neuroimaging (20), functional neuroimaging (52), or both (3), with or without cognitive testing.

\section{Results}

\section{Systematic Literature Review}

To examine the scientific evidence underlying our proposed theory, we conducted an evidence-based review of the literature, which ultimately included 85 studies examining the role of the dACC in OCD according to the criteria discussed above (Fig. 1). The bulk of this evidence (72 of 85 studies) consisted of neuroimaging studies, particularly functional neuroimaging (functional MRI [fMRI], PET, SPECT), which provides support for the hypothesis that dACC dysfunction is important in OCD pathophysiology. First, 23 resting-state functional neuroimaging studies were identified in our analysis. These studies have generally demonstrated that the dACC is hyperactive (13 of 23 studies) at rest in $\mathrm{OCD}, 6,22,24,27,49,62,63,76,85,87,111,140,142$ although some (5 of 23 studies) have shown decreased activity $9,20,126,128,151$ or no difference ${ }^{78,84,127,130}$ (4 of 23 studies) compared with controls.

Task-based studies have shown variable results, depending on the type of task, study design, differences in image analysis, and medication status of the OCD patients, among other factors. In general, however, task-based studies involving dACC function have focused on conflict, response inhibition, symptom provocation, and task or set switching. Twelve studies examining the role of con- 

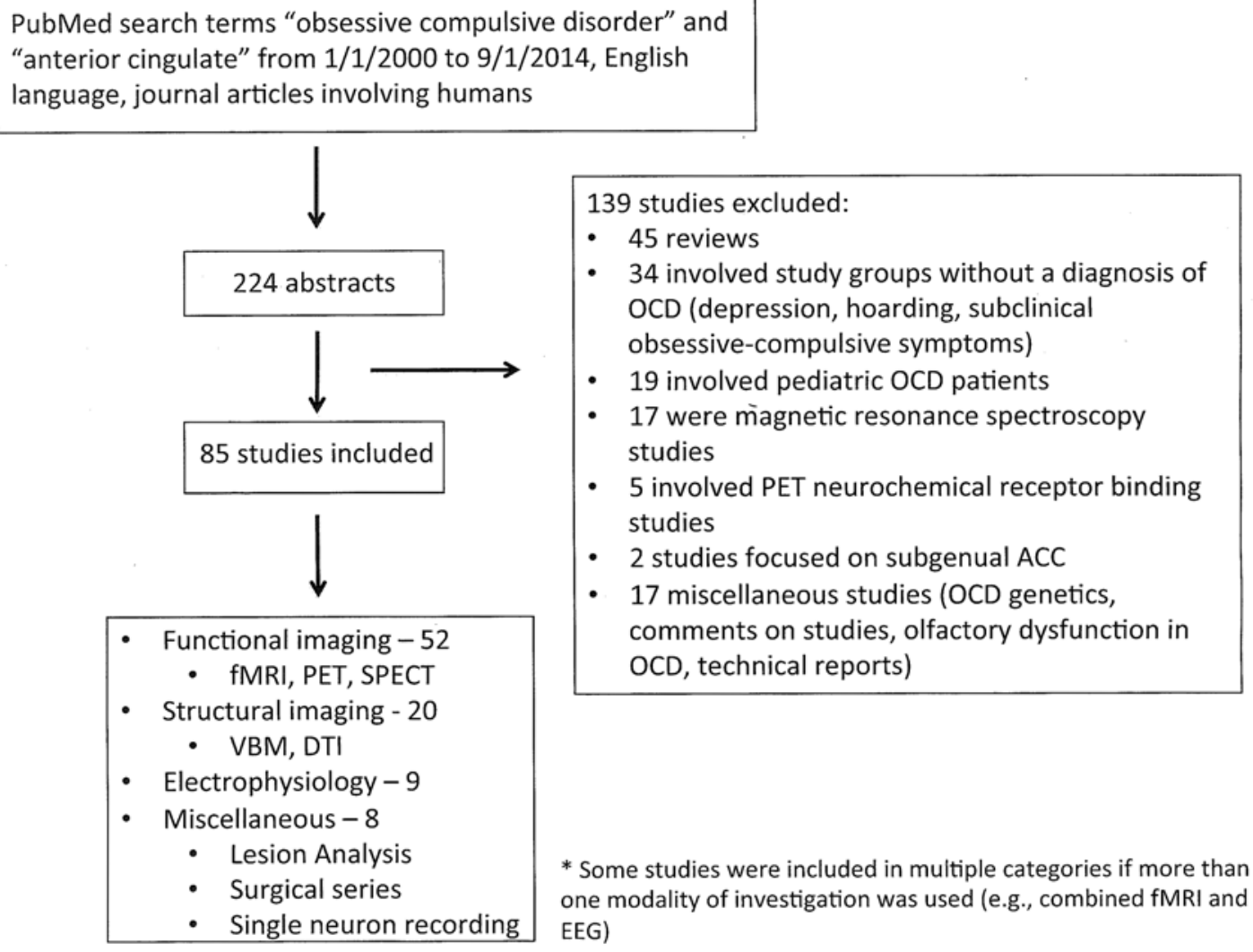

FIG. 1. PRISMA flow diagram of literature review methods; 224 abstracts were obtained by searching the PubMed terms "obsessive compulsive disorder" and "anterior cingulate" over a 14-year period. After excluding 139 studies, 85 were included for review, the majority of which (72) were neuroimaging studies.

flict and/or response inhibition were identified, with some studies demonstrating dACC hyperactivity during highconflict tasks or response inhibition ${ }^{28,41,98,143,158}$ while others have shown the opposite $e^{30,76,114,115,136}$ or no change at all. ${ }^{99,156}$ On the other hand, electrophysiological measures of conflict and error monitoring in OCD patients have generally found an enhancement in error-related negativity (ERN) or event-related potential activity (thought to reflect dACC activity) during task performance. , $29,45,82,118$ The evidence underlying the role of dACC in symptom provocation and task or set switching is equivocal, with too few studies to make concrete conclusions. ${ }^{1,26,51,57,112,132,164}$

Finally, the majority of structural neuroimaging studies have shown reduced cortical thickness or gray matter volume (10 of 20 studies) in the dACC $43,59,62,83,100,149,155$, 157,162 or reduced white matter volumes ( 3 of 20 studies) in the cingulum bundle, ${ }^{52,90,153}$ with no studies demonstrating an increase in gray or white matter volume and a few studies showing no change $\mathrm{e}^{7,23,77,133,135}$ or hemispheric variability. ${ }^{21}$

Thus, these studies represent the evidence base underlying our proposal and can help to inform our hypothesis linking dACC dysfunction and the effectiveness of psychiatric neurosurgical procedures targeting the dACC. Because our proposed theory is centered on dACC function and represents a departure from traditional models underlying OCD pathophysiology, any discussion of this proposal should begin with the current models of OCD dysfunction to understand how our hypothesis has emerged from these models.

\section{Current Model: CSTC Architecture}

The prevailing theory regarding the neurobiology of OCD consists of the cortico-striato-thalamo-cortical (CSTC) loop model. ${ }^{3}$ In this model, regions of cortex, basal ganglia, and thalamus that subserve related functions are anatomically and functionally interconnected (Fig. 2A). While the specific regions differ, each loop contains 2 pathways - a direct pathway that is net excitatory and an indirect pathway that is net inhibitory. Specifically, 2 distinct loops have been proposed to be dysregulated in OCD. ${ }^{141,159}$ First, a loop involving the OFC and ventromedial caudate has been shown to be hyperactive in OCD patients. ${ }^{13,17,130,152}$ Originally, an imbalance between the direct and indirect pathways resulting in OFC loop hyperactivity was proposed as the main factor underlying pathology seen in OCD. ${ }^{141}$ This circuit is thought to be involved in the motor response to emotionally salient stimuli. This theory postulates that excess activity in the circuit is responsible for the repetitive, stereotyped behaviors seen in OCD, as excess tone in this pathway lowers the threshold to permit ritualistic, compulsive behaviors. ${ }^{141}$

Over time, evidence from neuroimaging studies indicated that a second loop consisting of the dorsolateral 

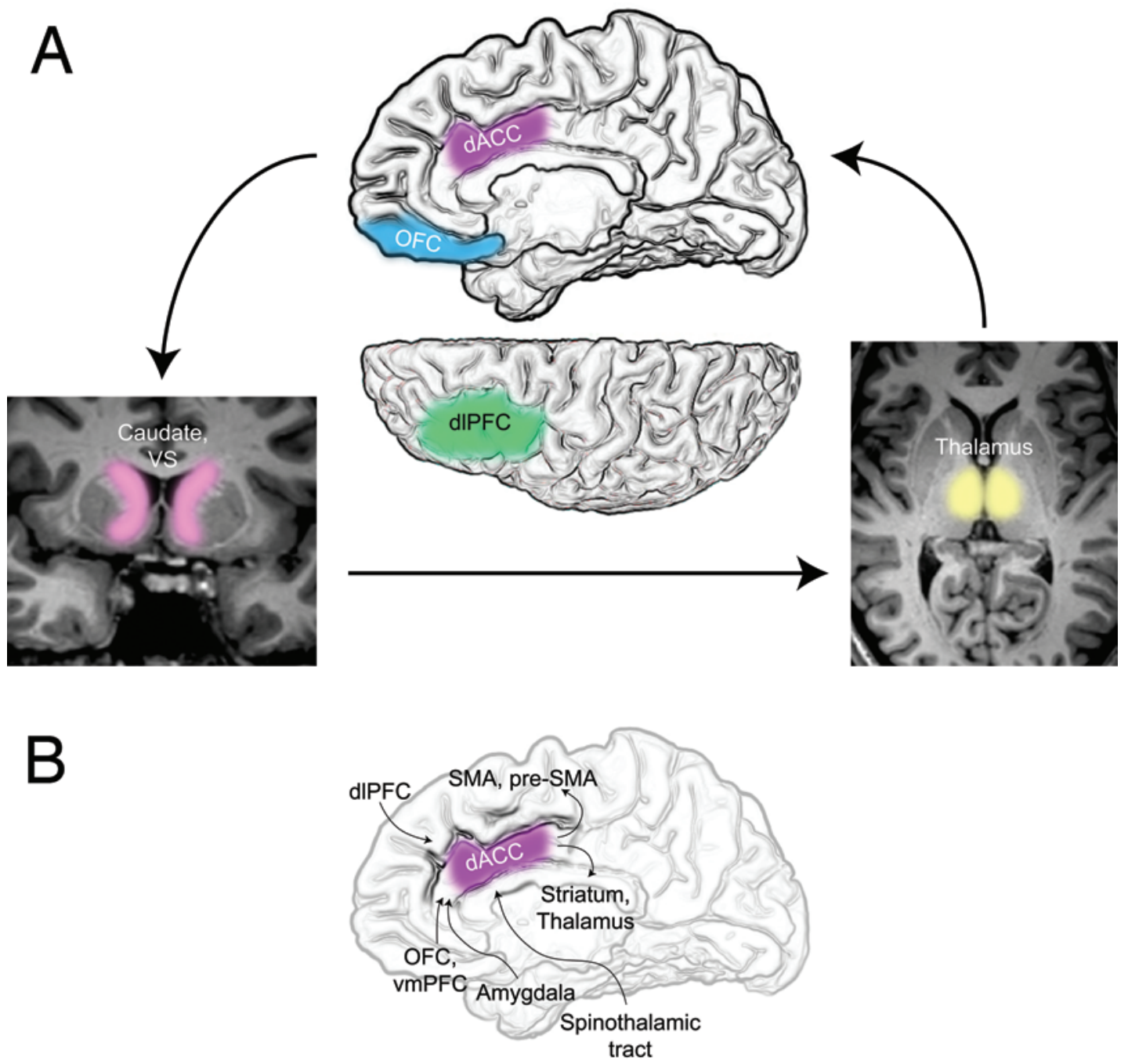

FIG. 2. Models of the neurobiology of OCD. A: The traditional CSTC model. Regions of the AACC, OFC, and dorsolateral prefrontal cortex (dIPFC) are connected with the caudate and VS, as well as the ventral anterior and mediodorsal thalamus. B: The $\mathrm{dACC}$ is ideally situated at the interface between sensory input streams, cognitive and affective processing regions, and structures regulating behavioral output. Copyright Sameer $A$. Sheth. Published with permission. Figure is available in color online only.

prefrontal cortex (dIPFC) and dorsolateral caudate ${ }^{86,141}$ is hypoactive in patients with OCD. This hypoactivity is thought to underlie the cognitive inflexibility and deficits in executive function seen on neuropsychological assessments in OCD patients. Thus, the prevailing hypothesis asserts that an imbalance between these 2 circuits is the underlying basis for OCD, as a hyperactive OFC generates obsessions and their associated ritualistic compulsions, while a hypoactive executive network prevents the individual from being able to switch to a new behavior. ${ }^{141,159}$

While the CSTC loop hypothesis has dominated the OCD literature over the last decade, recent efforts have been made to refine it. ${ }^{106}$ Anatomical studies have demonstrated that although there is a functional and topographic organization to fronto-striatal projections, the striatal anatomy is actually much more complex and contains more integration between regions than previously thought. Indeed, projections from the vmPFC, OFC, and $\mathrm{dACC}$ overlap and converge throughout adjacent regions of the striatum, ${ }^{53}$ a finding confirmed in human diffusion tensor imaging studies.$^{38}$ In fact, striatal GABAergic interneurons receiving convergent input are more responsive to cortical input than the typical striatal medium spiny neuron, ${ }^{53,96}$ underscoring the importance of multidimensional integration. In addition, studies examining reward pathways have also demonstrated the sequential activation of adjacent striatal regions beginning with the VS (including the nucleus accumbens), a region known to have direct projections from reward-related dopamine neurons, and ending with the dorsal caudate, a region with fewer connections to reward circuitry..$^{14}$ This evidence has led to the modern proposition that information is carried in "spirals," rather than isolated "loops," such that each adjacent region of the striatum integrates information from cortical, nigral, and limbic inputs and then sends that information to adjacent striatal regions and the thalamus..$^{53,106}$

As the nature of this integrative process has become apparent over time, more attention has been paid to po- 
tential "hubs" in the neurocircuitry thought to underlie OCD, with the idea that functional modulation of these hubs could lead to symptom improvement. In particular, the role of the dACC has come into focus, as its connectivity highlights its potential as a hub of cognitive control (Fig. 2B). Originally identified within a separate loop including the VS, ventral pallidum, and mediodorsal thalamus, ${ }^{3}$ the dACC has also been considered a component of other loops, including the vmPFC affective loop. ${ }^{106}$ Regardless of the loop nomenclature, the dACC has been shown to be hyperactive in a number of fMRI, 1,17,27,50,98,164 PET, ${ }^{102,123,130,152}$ and SPECT studies ${ }^{94}$ of OCD. However, other studies have demonstrated downregulated or unchanged dACC activity. $52,56,67,78,124$

The dACC has extensive reciprocal cortical connections with lateral prefrontal cortical (IPFC) regions, particularly the dlPFC, which are thought to underlie cognitive flexibility and executive function. Lateral PFC efferents mainly project onto cingulate motor regions, which are somatotopically organized and project to primary, premotor, and supplementary motor cortices. ${ }^{121,122}$ This organization places the dACC in an ideal position to both receive incoming sensory information and act on that information via downstream motor regulators.

\section{Beyond CSTC: Fear Extinction}

One of the initial findings leading to the CSTC hypothesis was the fact that symptom provocation did not activate subcortical and limbic structures in OCD patients as strongly as in patients with other types of anxiety disorders. ${ }^{129,130}$ Over time, however, we have increasingly recognized that abnormalities in fear learning, conditioning, and expression may contribute to the symptoms seen in OCD. Pavlovian fear conditioning pairs a neutral stimulus such as a sound (conditioned stimulus [CS]) with an inherently aversive stimulus such as a mild electric shock (unconditioned stimulus [US]). As the CS is repeatedly paired with the US over time, the subject associates the CS with fear and will begin to demonstrate the fear response to the CS itself. When the CS/US association is weakened (for example, by providing the sound without the shock), the fear response to the CS decreases as well, a term called "fear extinction." Although formulated over a century ago, this model is still relevant today.

Fear extinction may be deficient in patients with OCD (for review ${ }^{106}$ ), as they demonstrate electrophysiological signs of reduced fear extinction, ${ }^{116}$ with increased activation of the vmPFC and decreased activation of the dACC on fMRI when undergoing fear conditioning tasks. ${ }^{104} \mathrm{Fear}$ extinction is an important part of ERP, an effective form of cognitive-behavioral therapy for OCD in which patients are gradually exposed to their specific obsessions and then trained to prevent ritualistic behaviors. ${ }^{31,60}$ Structural MRI studies of the dACC have shown that its cortical thickness correlates with measures of fear learning, such as galvanic skin response, ${ }^{105}$ and have actually shown cortical thickness reductions in the $\mathrm{dACC}$ in patients who respond to ERP. ${ }^{43}$

Thus, while it is likely that vmPFC, amygdala, and other limbic structures are the main contributors to the deficits in fear extinction and aversive learning seen in OCD patients, the subcortical and limbic connections of the dACC place this structure within this circuit as well (Fig. 2B). For example, the dACC receives direct input from the spinothalamic tract, which relays sensory information on pain from the periphery. ${ }^{144}$ In addition, the substantia nigra and VS, mainly implicated in reward-related learning but also activated by a wide range of aversive stimuli, have projections to and from the dACC, respectively. ${ }^{18,167}$ Finally, the lateral basal nucleus of the amygdala, implicated in the avoidance learning of aversive stimuli, projects to both ventral and dorsal ACC. . $2,109^{2}$

Interestingly, an example of the convergence of pain, negative affect, motor activity, and cognition in the dACC lies in the control of facial expressions. The monkey homolog of dACC projects directly to neurons in the facial nucleus that control muscles of the upper face, ${ }^{110}$ and stimulation can produce facial expressions associated with the primate flight or fight response. ${ }^{144}$ In humans, these muscles produce characteristic facial expressions demonstrating anger, fear, and pain, some of which (for example, brow furrowing) are also observed during significant cognitive effort. ${ }^{144}$

\section{Control Signal Theory of dACC Function}

We now discuss dACC function from the cognitive neuroscience viewpoint. This literature has implicated the dACC in several cognitive processes including performance monitoring, action selection, and goal-directed behavior. ${ }^{61}$ The dACC appears to be specifically activated in tasks that require significant cognitive effort, as well as negative feedback, pain, and other aversive cues (Fig. 3). ${ }^{144}$ As neuroscientists continue to appreciate the connectivity of the dACC and its role in these neurocognitive processes, theories attempting to integrate these roles have begun to emerge. . $1,144,145^{-14}$

One common point of agreement across these models is the role of the dACC in cognitive control. As discussed above, "cognitive control" refers to the ability to attend to decision-relevant information while ignoring irrelevant information; inhibiting rapid, prepotent, "automatic" responses in favor of slower but better reasoned responses; monitoring outcomes of these responses; and adjusting behavior according to shifting goals or situations. Performing the Stroop test is a classic example of the requirement for cognitive control. When instructed to name the color of the ink in which a word is written, participant response times are longer when the identity of the word and the color of the ink are incongruent (for example, the word "red" written in green ink). In contrast, when participants are given no instruction or are instructed to read the word, response times are significantly faster, indicating that the processes involved in reading the word are automatic, whereas ignoring the word identity and attending to ink color requires suppression of a prepotent response and the engagement of cognitive control. Realworld examples include rapid decision making in the face of a threat (deciding to hit the brake or accelerator when approaching an intersection with a yellow traffic light) or motor adjustments in the face of changing environmental stimuli (adjusting one's swing to hit an off-speed pitch after 2 fastballs). Behavioral economics applications of 

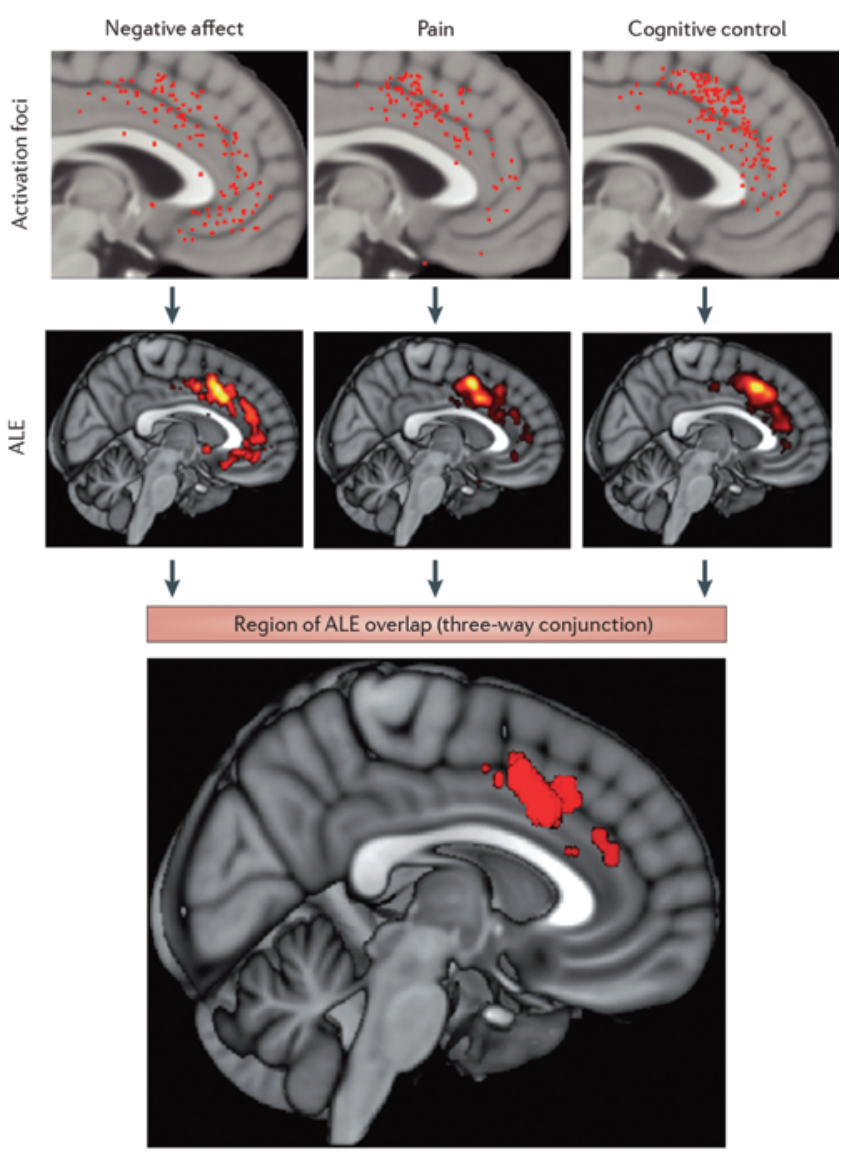

$40 \quad 30$

20

10

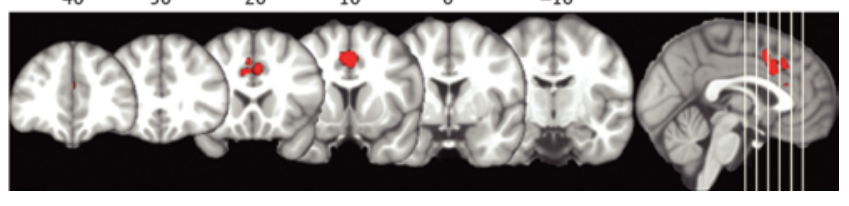

FIG. 3. The dACC is activated in studies involving negative affect, cognitive control, and pain. A coordinate-based meta-analysis of nearly 200 functional neuroimaging studies in humans demonstrates the $\mathrm{dACC}$ as the overlapping region activated in all 3 types of studies. ALE = activation likelihood estimate. Reprinted by permission from Macmillan Publishers Ltd: Nature Reviews Neuroscience, Shackman AJ et al: Nat Rev Neurosci 12:154-167, copyright 2011. http://www.nature.com. Figure is available in color online only.

this concept are keenly articulated in Nobel Prize-winning economist Daniel Kahneman's book Thinking, Fast and Slow. ${ }^{75}$

A recently elaborated theory of dACC function has attempted to encapsulate the various roles previously attributed to the dACC in cognitive control. According to the expected value of control (EVC) theory, the dACC estimates a quantity known as the EVC, the sum of the anticipated positive and negative outcomes of a "controlled" decision. ${ }^{145}$ Benefits of exerting control to correctly execute the task in light of long-term goals (for example, reward of correct performance) are weighed against the cost (effort, time, expense) of exerting control. This information is conveyed in the form of a control signal to downstream motor/ behavioral effectors. In the Stroop example, as incoming information (for example, visual processing of ink color and language processing of word identity) is monitored for relevance to the specified rule (attend to the color, not the identity), the possible outcomes (size of reward if answered correctly vs size of punishment if answered incorrectly) are weighed against the costs associated with the choice to exert cognitive control (time and effort), and the appropriate amount of control is exerted. In the traffic light example, the benefit of exerting control (avoiding a collision or ticket) is weighed against its cost (effort, the need to pause an ongoing conversation), and the dACC control signal allows the appropriate allocation of resources to make the optimal decision.

The generator of this control signal requires access to information regarding long-term goals and incoming contextual information, as well as efferent connections to control allocation centers that can influence behavior. The $\mathrm{dACC}$ is an excellent candidate region for estimating EVC given the range of afferent inputs (cortical, limbic, nigral, spinothalamic) and efferent projections (lateral prefrontal, motor) detailed above. The control signal is thought to be passed on to "regulatory centers" (probably the dlPFC) that use the signal to exert top-down control over downstream effectors (motor, cognitive, emotional) of the chosen behavioral plan. A number of human and monkey electrophysiological and imaging studies support the EVC conceptualization of dACC function. $4,5,16,25,34,36,55,69,81,101,139,146,165,168$

Critical to the EVC theory, and to our argument below, are the 2 defining components of this signal: identity and intensity. The control signal must specify both which control-requiring task (of potentially several) to pursue and how intently to pursue it. Details regarding this conceptualization can be found in the original paper, ${ }^{145}$ but this requirement does accord with intuition. The identity of the chosen task must be specified to allow regulatory regions to mobilize the appropriate machinery to accomplish it, and the intensity of engagement will certainly impact both the cost of control and the likelihood of success. An error in identity specification will lead to the pursuit of tasks misaligned with long-term goals. An error in intensity specification will lead to too little control (and subsequent failure in the task) or too much control (and inappropriate persistence in a task that should have been abandoned).

In the following proposal, we apply EVC concepts to suggest how dACC dysfunction can contribute to the symptomatology observed in OCD.

\section{Proposal: the dACC Aberrant Control Signal Hypothesis}

Given the evidence presented above, we advance the hypothesis that dACC dysfunction and resultant aberrant cognitive control signal specification contributes to the pathophysiology underlying OCD symptoms and behaviors (Fig. 4). Specifically, we propose that the observed behaviors arise from errors in specification of the identity and/or intensity of cognitive control signals.

The mis-specification of control signal identity drives the pursuit of tasks that do not accord with long-term goals. The performance of such tasks would produce negative feedback, including delays in attaining the overall goal, omission of expected rewards, discomfort or pain, errors, or other negatively valenced outcomes. In the healthy scenario, these indicators of suboptimal behavior would 

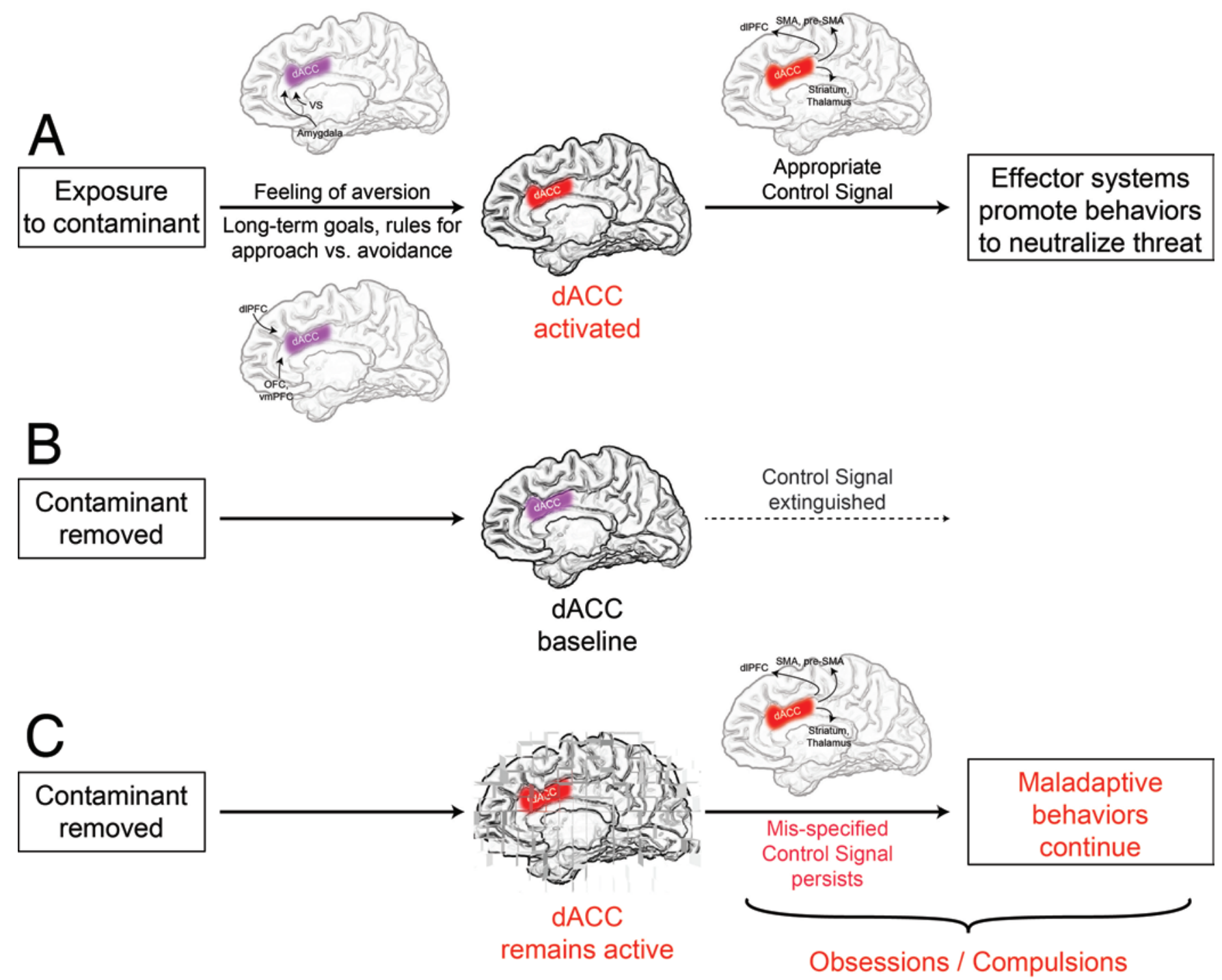

FIG. 4. Proposed control signal theory of dACC dysfunction in OCD. A: The subject is exposed to an aversive stimulus, for example, a contaminant in the environment. Regions such as the amygdala and VS produce feelings of displeasure and aversion, and cortical areas including the OFC, vmPFC, and dIPFC coordinate an avoidance response based on established goals. Connectivity to the dACC results in its activation, as it detects the anxiety and negative affect of the current state (contamination). It, therefore, generates an appropriate control signal to downstream effector regions, including the dIPFC, pre-supplementary motor area (SMA), and SMA, which in turn promote behaviors to remove the threat (washing). B: In a healthy subject, removing the threat leads to baseline restoration of $\mathrm{dACC}$ activity, extinguishing of the $\mathrm{dACC}$ control signal, and cessation of the behavior. C: In a patient with OCD, however, the dACC remains pathologically active despite removal of the threat, potentially because of persistent activity in other regions, such as the OFC or striatum (not shown). Unable to silence the alarm, the dACC continues to generate a mis-specified control signal (see Proposal: the dACC Aberrant Control Signal Hypothesis for mis-specification scenarios). Persistence of the control signal results in a continuation of the now maladaptive behaviors. The emotional distress related to the persistence of control signals and the continued behaviors fruitlessly attempting to assuage these feelings may represent an important neurobiological component of obsessions and compulsions, respectively. Copyright Sameer A. Sheth. Published with permission. Figure is available in color online only.

trigger the dACC to adjust its control signal and identify a different behavior. In the dysfunctional scenario, these indicators do not readily extinguish the previous behavior to produce an adaptive change in strategy.

Neurocognitive studies provide several examples of this phenomenon in patients with OCD. First, OCD patients typically describe their symptoms as difficulty in stopping their behavior. ${ }^{64,131}$ Indeed, behavioral studies have shown that OCD patients tend to have few, extended episodes of compulsive behavior rather than frequent episodes of short duration. ${ }^{64}$ For example, patients with hand-washing compulsions demonstrate extended episodes of hand washing even if their initial sensitivity to the threat of germs is similar to that in control subjects. ${ }^{58}$ In addition, individuals with OCD change their behavior more slowly after making a mistake while completing a task, ${ }^{161}$ indicating difficulty 
reassigning the identity of a new behavior despite evidence that the current behavior is maladaptive. This cognitive inflexibility has been associated with altered fMRI activation of the dACC and other cortical areas. ${ }^{51,161}$

Mis-specification of control signal intensity (hyperintense signal in this example) places inappropriately elevated importance on a particular (internal or external) stimulus despite evidence that the stimulus does not warrant such attention. A hyperintense dACC control signal would allocate substantial cognitive resources toward generating behaviors to address the perceived threat, repulsion, or conflict represented by the stimulus. In the healthy scenario, realization of the benign nature of the stimulus would rapidly drive down the intensity of the control signal and extinguish those behaviors. In the dysfunctional scenario, maneuvers to address the perceived offending stimulus are unable to reduce the intensity of the control signal. Thus the anxiety remains, and the futile, unnecessary, or unprofitable behaviors persist. This dysfunction in control signal intensity can therefore manifest as threat overestimation. Moreover, the inability to eliminate the threat despite the "need" to do so can produce an over-inflated sense of personal responsibility. Both threat overestimation and an exaggerated sense of responsibility are often observed in OCD. ${ }^{71,113,154}$

Together, these mis-specified control signals produce a phenotype in which there is a persistent anxiety-producing sense of threat or unease generated by otherwise innocuous stimuli that cannot be extinguished. Repetitive behaviors to reduce this distress signal are ineffective, but the individual persists with these maladaptive behaviors, unable to abandon them and switch to more useful strategies (Fig. 4). The contamination and cleansing dimension of OCD serves as an example. Overestimating the threat of germs and exaggerating the importance of the act of cleansing lead to contamination obsessions and washing compulsions. Unable to quench the feeling of threat from the contaminant, the individual continues to perform the exaggerated cleansing rituals.

As another example, the persistence of a signal indicating that a task is still "unfinished" can produce the obsession of incompleteness, and the inability to switch to a different behavior produces the associated perseverative checking compulsions. Whereas a fleeting thought about whether one has actually locked the door may induce momentary concern in an unaffected individual, mis-specified control signals in OCD can allow that concern to persist despite repeated attempts to extinguish it. Similarly, obsessions of disorder and compulsions for ordering and symmetry can be thought of as control signals for orderliness that are never assuaged and cannot be changed.

This framework may also be useful for understanding the impaired fear extinction seen in OCD patients. ${ }^{104}$ In the classical conditioning example described above, fear extinction requires realizing that a CS (for example, sound) is no longer associated with an US (for example, electric shock). In the case of a dysfunctional dACC mis-specifying control signals, the CS's label of "threat" is carried for longer than usual, and the individual has a difficult time abandoning the fear associated with the perceived threat. The dACC is activated during threat assessment, ${ }^{40}$ and threat overestimation has been linked with the generalization of fear in OCD patients. ${ }^{74}$ Thus dACC dysfunction may also contribute to the impaired fear extinction seen in OCD patients.

Of course while a dysfunctional dACC is central to our proposed model, it is not the sole component of the affected network. As discussed above, the dACC is part of a cognitive/affective network including the OFC, vmPFC, dlPFC, and associated subcortical and limbic structures. All of these structures perform in a coordinated fashion; thus there may be nuances to the produced behaviors in OCD resulting from various contributions of other network components. In fact, the degree and nature of their involvement may influence the dimension of symptoms (contamination/cleaning, symmetry/ordering, forbidden thoughts/checking, and so forth) in these patients. Nonetheless, we propose that the dACC aberrant control signal hypothesis is a useful prism through which to conceptualize OCD symptoms and behaviors.

\section{Therapeutic Effect of dACC Lesions in OCD}

If dACC dysfunction is a key factor underlying the pathology seen in OCD, it is reasonable to pursue the hypothesis that modulating $\mathrm{dACC}$ function will improve the symptoms of OCD. The effect of dACC modulation for the treatment of OCD was noticed as early as the 1950s when a group in Oxford performed bilateral ACC resections in patients with a variety of psychiatric diagnoses on the basis of monkey studies and postmortem examination of patients who had undergone frontal lobotomy. ${ }^{166}$ While cingulectomy had minimal effect on patients with schizophrenia, remarkable improvement was noted in patients with primarily obsessive or anxiety-related symptoms. ${ }^{166}$

Stereotactic cingulotomy was developed by Ballantine in the 1960s, partly inspired by the English experience. ${ }^{10}$ Early results in the MRI era demonstrated a significant response in at least $25 \%-30 \%$ of patients. ${ }^{68}$ Updated results using the Yale-Brown Obsessive-Compulsive Scale (YBOCS) demonstrated at least partial response $(\geq 25 \%$ improvement on YBOCS) in $45 \%$ (20) of 44 patients treated with bilateral cingulotomy. ${ }^{37}$ More modern surgical series have demonstrated similar results, although the preponderance of clinical evidence remains Class II or III (Table 1). ${ }^{32,33,35,46,47,65,70,72,73,88,91,95,117,137,147,172,173}$ One study with a 5-year mean follow-up in 64 patients recently showed that $69 \%$ obtained at least a partial response, and $47 \%$ attained a full response ( $\geq 35 \%$ YBOCS improvement). ${ }^{147}$ Another group demonstrated similar results, with a $47 \%$ full response rate (using similar criteria) to bilateral cingulotomy in 17 patients with a 2 -year follow-up. ${ }^{73}$ Given the fact that years and often decades of conventional pharmacological and cognitive-behavioral therapy had failed in all of these patients, this degree of improvement is substantial.

Neuromodulation of other nodes in the network is also effective in treating OCD. Lesions in the anterior limb of the internal capsule (ALIC), using either radiofrequency ablation or stereotactic radiosurgery, have shown efficacy for decades. ${ }^{119}$ Recently, high-frequency MR-guided ultrasonography has been developed as a noninvasive technique to create lesions and has been effectively used to create capsulotomies in patients with pharmacoresistant 


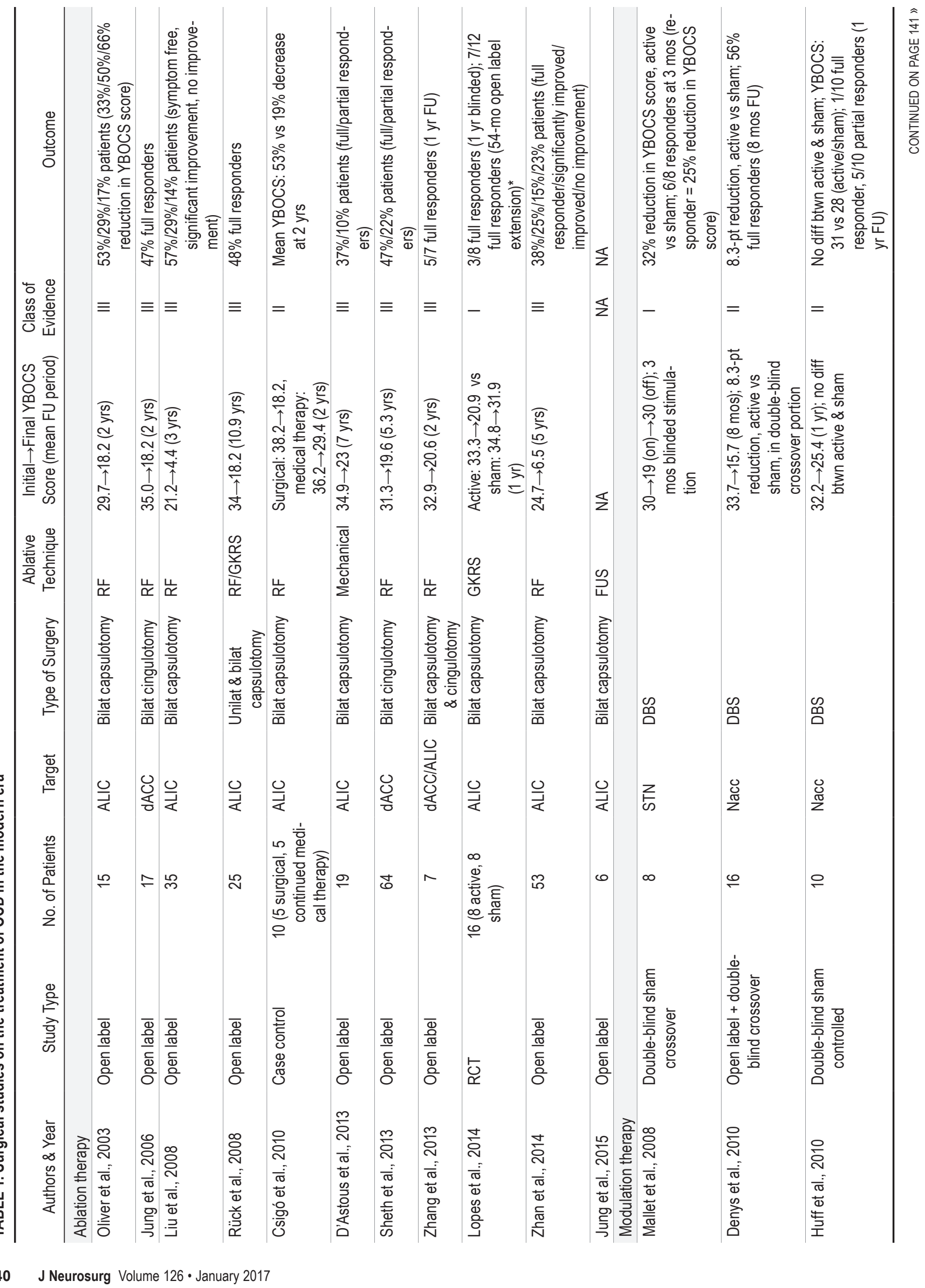




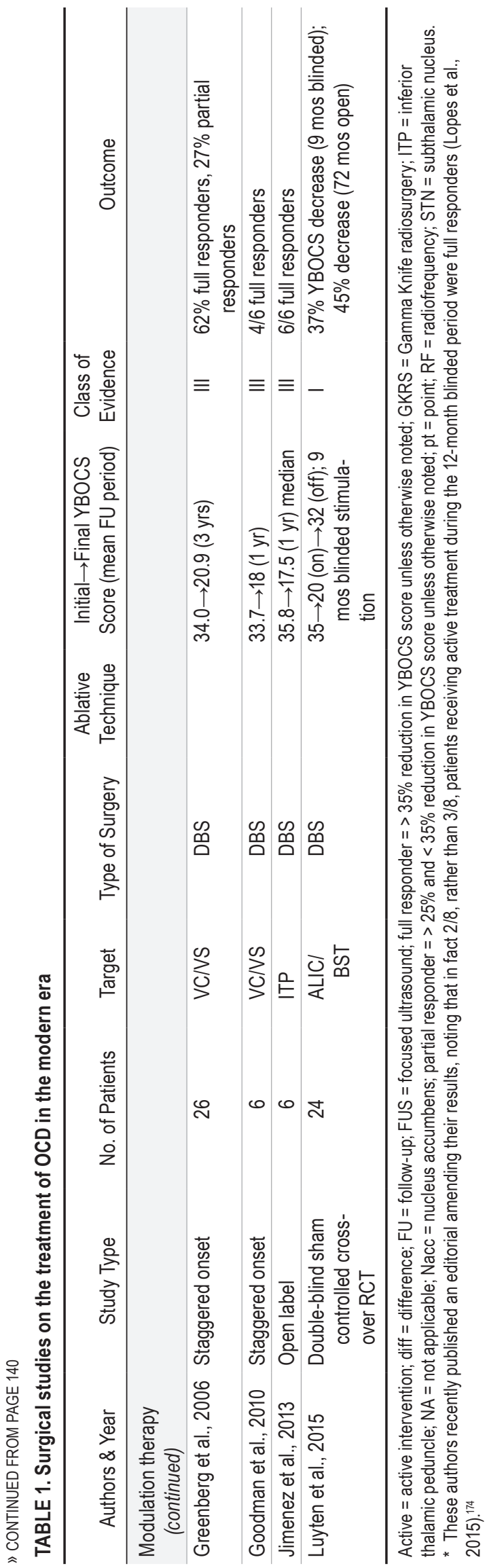

OCD. ${ }^{72}$ The first double-blind randomized controlled trial (RCT) of capsulotomy lesions showed promising results, further supporting the role of therapies in this target. ${ }^{91,174}$

Furthermore, DBS of several involved nodes has proven to be effective in severe, refractory OCD. ${ }^{54} \mathrm{~A}$ number of evidence Class II and III studies in the ventral ALIC/VS (VC/VS target), ${ }^{46-48}$ the nucleus accumbens (a subregion of the VS), ${ }^{35,65}$ and the inferior thalamic peduncle ${ }^{70}$ have shown promising results. A Class I, double-blind, crossover RCT of DBS in the subthalamic nucleus has also demonstrated benefit. ${ }^{95}$ Most recently, a double-blind, randomized, crossover study of DBS targeting the junction of the ALIC and bed nucleus of the stria terminalis has provided further Class I evidence for the benefit of DBS. ${ }^{93}$ Affective/limbic cortical regions including the dACC, OFC, and vmPFC are connected to the VS and other regions of the basal ganglia and thalamus via the ALIC. Because modulation of a node, with either targeted lesions or electrical stimulation, is not merely a local event but propagates through the network, it is not surprising that several targets are effective. Future investigation will reveal whether certain forms or targets of modulation are more effective for certain patients or symptom dimensions than others.

\section{Applicability to Other Diseases}

Our proposed theory also explains the effectiveness of dACC neuromodulation for other disorders such as chronic neuropathic pain and depression. As previously discussed, the dACC appears to be significantly involved in fear expression, negative affect, and pain. A recent meta-analysis of nearly $200 \mathrm{fMRI}$ studies showed that pain, negative affect, and cognitive control all activate an overlapping region of the dACC (Fig. 3), arguing that the dACC acts as a hub that processes negative emotional and reinforcing information and then uses that information to direct motivated behavior. ${ }^{144}$ It is therefore likely that disease processes that include negative affect, such as depression or chronic neuropathic pain, can be treated with dACC modulation. While we have focused on cognitive control in this review because of its relationship to OCD, cingulotomy has indeed been effective in patients with chronic, intractable neuropathic pain..$^{42,80,125,163,169-171}$ Recently, the first case series of dACC DBS for chronic pain was reported with similar results. ${ }^{15}$ In addition, cingulotomy, ${ }^{148}$ subgenual cingulate DBS, ${ }^{79,92}$ and VC/VS DBS ${ }^{97}$ have all been shown to be effective in treating refractory depression.

\section{Conclusions and Predictions}

In this proposal we sought to establish a neurobiological basis for the efficacy of neuromodulatory procedures targeting the dACC for the treatment of refractory OCD. In doing so, we synthesized the neuroscientific literature on cognitive control and the psychiatric neurosurgical literature on targeted treatments for OCD. We propose that the mis-specification of cognitive control signals by the dACC is a key element in generating the obsessive thoughts and compulsive behaviors in OCD. We have focused on deficiencies in cognitive control as a central feature of this symptomatology. This emphasis is supported by our litera- 
ture review and concords with the NIMH RDoC classification matrix. It should be noted that while the diagnosis of OCD probably has components within other RDoC domains, potentially including "Negative Valence Systems" (constructs of "Fear," "Anxiety") and "Positive Valence Systems" (construct of "Approach Motivation"), the largest projection probably lies in the Cognitive Control construct.

Our proposal makes predictions that can be readily tested. There are a number of ways to measure cognitive control, including behavioral tasks (Stroop, Simon, Eriksen flanker, multisource interference, go/no-go, stop signal, set switching, and so forth), functional imaging (task-based fMRI), and electrophysiology (temporal and spectral domain electroencephalography [EEG]). Whereas a number of studies have investigated differences in these measures between patients with OCD and healthy controls, very few have done so longitudinally in patients before and after targeted treatments. Our theory would predict that measures of cognitive control would change in parallel with therapeutic efficacy. Moreover, we would predict that imaging or electrophysiological measures of dACC function would return toward normal (for example, normalizing fMRI activation, normalizing ERN amplitude and spectral measures on EEG), also in parallel with clinical response. This pattern would be particularly interesting to study in the context of procedures that do not target the dACC. For example, how would these measures change following capsulotomy or DBS in the VC/VS or subthalamic nucleus? It is unlikely that benefit following cingulotomy would, from a mechanistic standpoint, differ substantially from benefit following other targeted procedures. We would predict that downstream effects of those procedures would still result in normalization of dACC function in parallel with clinical response.

Future work in this field will, we hope, further dissect the role of the dACC and other cortical and subcortical regions in the pathogenesis of OCD and other disorders of cognitive control. As we improve our understanding of the normal physiology and function of these networks, we will be better equipped to successfully treat disorders arising from their dysfunction.

\section{References}

1. Adler CM, McDonough-Ryan P, Sax KW, Holland SK, Arndt S, Strakowski SM: fMRI of neuronal activation with symptom provocation in unmedicated patients with obsessive compulsive disorder. J Psychiatr Res 34:317-324, 2000

2. Agam Y, Greenberg JL, Isom M, Falkenstein MJ, Jenike $\mathrm{E}$, Wilhelm S, et al: Aberrant error processing in relation to symptom severity in obsessive-compulsive disorder: A multimodal neuroimaging study. Neuroimage Clin 5:141-151, 2014

3. Alexander GE, DeLong MR, Strick PL: Parallel organization of functionally segregated circuits linking basal ganglia and cortex. Annu Rev Neurosci 9:357-381, 1986

4. Alexander WH, Brown JW: Medial prefrontal cortex as an action-outcome predictor. Nat Neurosci 14:1338-1344, 2011

5. Amemori K, Graybiel AM: Localized microstimulation of primate pregenual cingulate cortex induces negative decision-making. Nat Neurosci 15:776-785, 2012

6. Anticevic A, Hu S, Zhang S, Savic A, Billingslea E,
Wasylink S, et al: Global resting-state functional magnetic resonance imaging analysis identifies frontal cortex, striatal, and cerebellar dysconnectivity in obsessive-compulsive disorder. Biol Psychiatry 75:595-605, 2014

7. Atmaca M, Yildirim H, Ozdemir H, Tezcan E, Poyraz AK: Volumetric MRI study of key brain regions implicated in obsessive-compulsive disorder. Prog Neuropsychopharmacol Biol Psychiatry 31:46-52, 2007

8. Aycicegi A, Dinn WM, Harris CL, Erkmen H: Neuropsychological function in obsessive-compulsive disorder: effects of comorbid conditions on task performance. Eur Psychiatry 18:241-248, 2003

9. Baker KB, Kopell BH, Malone D, Horenstein C, Lowe M, Phillips MD, et al: Deep brain stimulation for obsessivecompulsive disorder: using functional magnetic resonance imaging and electrophysiological techniques: technical case report. Neurosurgery 61 (5 Suppl 2):E367-E368, 2007

10. Ballantine HT Jr, Cassidy WL, Flanagan NB, Marino R Jr: Stereotaxic anterior cingulotomy for neuropsychiatric illness and intractable pain. J Neurosurg 26:488-495, 1967

11. Bannon S, Gonsalvez CJ, Croft RJ, Boyce PM: Response inhibition deficits in obsessive-compulsive disorder. Psychiatry Res 110:165-174, 2002

12. Barbas H, De Olmos J: Projections from the amygdala to basoventral and mediodorsal prefrontal regions in the rhesus monkey. J Comp Neurol 300:549-571, 1990

13. Baxter LR Jr, Schwartz JM, Mazziotta JC, Phelps ME, Pahl JJ, Guze BH, et al: Cerebral glucose metabolic rates in nondepressed patients with obsessive-compulsive disorder. Am J Psychiatry 145:1560-1563, 1988

14. Belin D, Everitt BJ: Cocaine seeking habits depend upon dopamine-dependent serial connectivity linking the ventral with the dorsal striatum. Neuron 57:432-441, 2008

15. Boccard SGJ, Fitzgerald JJ, Pereira EAC, Moir L, Van Hartevelt TJ, Kringelbach ML, et al: Targeting the affective component of chronic pain: a case series of deep brain stimulation of the anterior cingulate cortex. Neurosurgery 74:628-637, 2014

16. Botvinick MM, Huffstetler S, McGuire JT: Effort discounting in human nucleus accumbens. Cogn Affect Behav Neurosci 9:16-27, 2009

17. Breiter HC, Rauch SL: Functional MRI and the study of OCD: from symptom provocation to cognitive-behavioral probes of cortico-striatal systems and the amygdala. Neuroimage 4:S127-S138, 1996

18. Bromberg-Martin ES, Matsumoto M, Hikosaka O: Dopamine in motivational control: rewarding, aversive, and alerting. Neuron 68:815-834, 2010

19. Brown LT, Mikell CB, Youngerman BE, Zhang Y, McKhann GM II, Sheth SA: Dorsal anterior cingulotomy and anterior capsulotomy for severe, refractory obsessivecompulsive disorder: a systematic review of observational studies. J Neurosurg 124:77-89, 2016

20. Busatto GF, Zamignani DR, Buchpiguel CA, Garrido GE, Glabus MF, Rocha ET, et al: A voxel-based investigation of regional cerebral blood flow abnormalities in obsessivecompulsive disorder using single photon emission computed tomography (SPECT). Psychiatry Res 99:15-27, 2000

21. Cannistraro PA, Makris N, Howard JD, Wedig MM, Hodge SM, Wilhelm S, et al: A diffusion tensor imaging study of white matter in obsessive-compulsive disorder. Depress Anxiety 24:440-446, 2007

22. Carey PD, Warwick J, Niehaus DJ, van der Linden G, van Heerden BB, Harvey BH, et al: Single photon emission computed tomography (SPECT) of anxiety disorders before and after treatment with citalopram. BMC Psychiatry 4:30, 2004

23. Cecconi JP, Lopes AC, Duran FL, Santos LC, Hoexter MQ, Gentil AF, et al: Gamma ventral capsulotomy for treatment 
of resistant obsessive-compulsive disorder: a structural MRI pilot prospective study. Neurosci Lett 447:138-142, 2008

24. Chang JW, Kim CH, Lee JD, Chung SS: Single photon emission computed tomography imaging in obsessivecompulsive disorder and for stereotactic bilateral anterior cingulotomy. Neurosurg Clin N Am 14:237-250, 2003

25. Chein JM, Schneider W: Neuroimaging studies of practicerelated change: fMRI and meta-analytic evidence of a domain-general control network for learning. Brain Res Cogn Brain Res 25:607-623, 2005

26. Chen XL, Xie JX, Han HB, Cui YH, Zhang BQ: MR perfusion-weighted imaging and quantitative analysis of cerebral hemodynamics with symptom provocation in unmedicated patients with obsessive-compulsive disorder. Neurosci Lett 370:206-211, 2004

27. Cheng Y, Xu J, Nie B, Luo C, Yang T, Li H, et al: Abnormal resting-state activities and functional connectivities of the anterior and the posterior cortexes in medicationnaïve patients with obsessive-compulsive disorder. PLoS One 8:e67478, 2013

28. Ciesielski KT, Rauch SL, Ahlfors SP, Vangel ME, Wilhelm $\mathrm{S}$, Rosen BR, et al: Role of medial cortical networks for anticipatory processing in obsessive-compulsive disorder. Hum Brain Mapp 33:2125-2134, 2012

29. Ciesielski KT, Rowland LM, Harris RJ, Kerwin AA, Reeve A, Knight JE: Increased anterior brain activation to correct responses on high-conflict Stroop task in obsessive-compulsive disorder. Clin Neurophysiol 122:107-113, 2011

30. Cocchi L, Harrison BJ, Pujol J, Harding IH, Fornito A, Pantelis C, et al: Functional alterations of large-scale brain networks related to cognitive control in obsessive-compulsive disorder. Hum Brain Mapp 33:1089-1106, 2012

31. Craske MG, Treanor M, Conway CC, Zbozinek T, Vervliet $\mathrm{B}$ : Maximizing exposure therapy: an inhibitory learning approach. Behav Res Ther 58:10-23, 2014

32. Csigó K, Harsányi A, Demeter G, Rajkai C, Németh A, Racsmány M: Long-term follow-up of patients with obsessive-compulsive disorder treated by anterior capsulotomy: a neuropsychological study. J Affect Disord 126:198-205, 2010

33. D'Astous M, Cottin S, Roy M, Picard C, Cantin L: Bilateral stereotactic anterior capsulotomy for obsessive-compulsive disorder: long-term follow-up. J Neurol Neurosurg Psychiatry 84:1208-1213, 2013

34. Danielmeier C, Eichele T, Forstmann BU, Tittgemeyer M, Ullsperger M: Posterior medial frontal cortex activity predicts post-error adaptations in task-related visual and motor areas. J Neurosci 31:1780-1789, 2011

35. Denys D, Mantione M, Figee M, van den Munckhof P, Koerselman F, Westenberg H, et al: Deep brain stimulation of the nucleus accumbens for treatment-refractory obsessive-compulsive disorder. Arch Gen Psychiatry 67:1061-1068, 2010

36. Dixon ML, Christoff K: The decision to engage cognitive control is driven by expected reward-value: neural and behavioral evidence. PLoS One 7:e51637, 2012

37. Dougherty DD, Baer L, Cosgrove GR, Cassem EH, Price $\mathrm{BH}$, Nierenberg AA, et al: Prospective long-term follow-up of 44 patients who received cingulotomy for treatmentrefractory obsessive-compulsive disorder. Am J Psychiatry 159:269-275, 2002

38. Draganski B, Kherif F, Klöppel S, Cook PA, Alexander DC, Parker GJM, et al: Evidence for segregated and integrative connectivity patterns in the human Basal Ganglia. J Neurosci 28:7143-7152, 2008

39. Eddy KT, Dutra L, Bradley R, Westen D: A multidimensional meta-analysis of psychotherapy and pharmacotherapy for obsessive-compulsive disorder. Clin Psychol Rev 24:1011-1030, 2004
40. Fiddick L: There is more than the amygdala: potential threat assessment in the cingulate cortex. Neurosci Biobehav Rev 35:1007-1018, 2011

41. Fitzgerald KD, Welsh RC, Gehring WJ, Abelson JL, Himle JA, Liberzon I, et al: Error-related hyperactivity of the anterior cingulate cortex in obsessive-compulsive disorder. Biol Psychiatry 57:287-294, 2005

42. Foltz EL, White LE Jr: Pain "relief" by frontal cingulumotomy. J Neurosurg 19:89-100, 1962

43. Fullana MA, Cardoner N, Alonso $\mathrm{P}$, Subirà M, López-Solà C, Pujol J, et al: Brain regions related to fear extinction in obsessive-compulsive disorder and its relation to exposure therapy outcome: a morphometric study. Psychol Med 44:845-856, 2014

44. Garnaat SL, Greenberg BD, Sibrava NJ, Goodman WK, Mancebo MC, Eisen JL, et al: Who qualifies for deep brain stimulation for OCD? Data from a naturalistic clinical sample. J Neuropsychiatry Clin Neurosci 26:81-86, 2014

45. Gehring WJ, Himle J, Nisenson LG: Action-monitoring dysfunction in obsessive-compulsive disorder. Psychol Sci 11: $1-6,2000$

46. Goodman WK, Foote KD, Greenberg BD, Ricciuti N, Bauer $\mathrm{R}$, Ward H, et al: Deep brain stimulation for intractable obsessive compulsive disorder: pilot study using a blinded, staggered-onset design. Biol Psychiatry 67:535-542, 2010

47. Greenberg BD, Gabriels LA, Malone DA Jr, Rezai AR, Friehs GM, Okun MS, et al: Deep brain stimulation of the ventral internal capsule/ventral striatum for obsessive-compulsive disorder: worldwide experience. Mol Psychiatry 15:64-79, 2010

48. Greenberg BD, Malone DA, Friehs GM, Rezai AR, Kubu CS, Malloy PF, et al: Three-year outcomes in deep brain stimulation for highly resistant obsessive-compulsive disorder. Neuropsychopharmacology 31:2384-2393, 2006

49. Greenspan JD, Coghill RC, Gilron I, Sarlani E, Veldhuijzen DS, Lenz FA: Quantitative somatic sensory testing and functional imaging of the response to painful stimuli before and after cingulotomy for obsessive-compulsive disorder (OCD). Eur J Pain 12:990-999, 2008

50. Gruner P, Vo A, Argyelan M, Ikuta T, Degnan AJ, John M, et al: Independent component analysis of resting state activity in pediatric obsessive-compulsive disorder. Hum Brain Mapp 35:5306-5315, 2014

51. Gu BM, Park JY, Kang DH, Lee SJ, Yoo SY, Jo HJ, et al: Neural correlates of cognitive inflexibility during task-switching in obsessive-compulsive disorder. Brain 131:155-164, 2008

52. Ha TH, Kang DH, Park JS, Jang JH, Jung WH, Choi JS, et al: White matter alterations in male patients with obsessivecompulsive disorder. Neuroreport 20:735-739, 2009

53. Haber SN, Knutson B: The reward circuit: linking primate anatomy and human imaging. Neuropsychopharmacology 35:4-26, 2010

54. Hamani C, Pilitsis J, Rughani AI, Rosenow JM, Patil PG, Slavin KS, et al: Deep brain stimulation for obsessivecompulsive disorder: systematic review and evidencebased guideline sponsored by the American Society for Stereotactic and Functional Neurosurgery and the Congress of Neurological Surgeons (CNS) and endorsed by the CNS and American Association of Neurological Surgeons. Neurosurgery 75:327-333, 2014

55. Hampton AN, O'Doherty JP: Decoding the neural substrates of reward-related decision making with functional MRI. Proc Natl Acad Sci U S A 104:1377-1382, 2007

56. Han JY, Kang DH, Gu BM, Jung WH, Choi JS, Choi CH, et al: Altered brain activation in ventral frontal-striatal regions following a 16-week pharmacotherapy in unmedicated obsessive-compulsive disorder. J Korean Med Sci 26:665-674, 2011 
57. Hendler T, Goshen E, Tzila Zwas S, Sasson Y, Gal G, Zohar J: Brain reactivity to specific symptom provocation indicates prospective therapeutic outcome in OCD. Psychiatry Res 124:87-103, 2003

58. Hinds AL, Woody EZ, Van Ameringen M, Schmidt LA, Szechtman H: When too much is not enough: obsessivecompulsive disorder as a pathology of stopping, rather than starting. PLoS One 7:e30586, 2012

59. Hoexter MQ, de Souza Duran FL, D'Alcante CC, Dougherty DD, Shavitt RG, Lopes AC, et al: Gray matter volumes in obsessive-compulsive disorder before and after fluoxetine or cognitive-behavior therapy: a randomized clinical trial. Neuropsychopharmacology 37:734-745, 2012

60. Hofmann SG: Enhancing exposure-based therapy from a translational research perspective. Behav Res Ther 45: 1987-2001, 2007

61. Holroyd CB, Yeung N: An integrative theory of anterior cingulate cortex function: option selection in hierarchical reinforcement learning, in Mars RB, Sallet J, Rushworth MFS, et al (eds): Neural Basis of Motivational and Cognitive Control. Cambridge: MIT Press, 2011

62. Hou J, Song L, Zhang W, Wu W, Wang J, Zhou D, et al: Morphologic and functional connectivity alterations of corticostriatal and default mode network in treatment-naïve patients with obsessive-compulsive disorder. PLoS One 8:e83931, 2013

63. Hou J, Wu W, Lin Y, Wang J, Zhou D, Guo J, et al: Localization of cerebral functional deficits in patients with obsessive-compulsive disorder: a resting-state fMRI study. J Affect Disord 138:313-321, 2012

64. Huey ED, Zahn R, Krueger F, Moll J, Kapogiannis D, Wassermann EM, et al: A psychological and neuroanatomical model of obsessive-compulsive disorder. J Neuropsychiatry Clin Neurosci 20:390-408, 2008

65. Huff W, Lenartz D, Schormann M, Lee SH, Kuhn J, Koulousakis A, et al: Unilateral deep brain stimulation of the nucleus accumbens in patients with treatment-resistant obsessive-compulsive disorder: Outcomes after one year. Clin Neurol Neurosurg 112:137-143, 2010

66. Insel T, Cuthbert B, Garvey M, Heinssen R, Pine DS, Quinn $\mathrm{K}$, et al: Research domain criteria (RDoC): toward a new classification framework for research on mental disorders. Am J Psychiatry 167:748-751, 2010

67. Jang JH, Kwon JS, Jang DP, Moon WJ, Lee JM, Ha TH, et al: A proton MRSI study of brain $\mathrm{N}$-acetylaspartate level after 12 weeks of citalopram treatment in drugnaive patients with obsessive-compulsive disorder. Am J Psychiatry 163:1202-1207, 2006

68. Jenike MA, Baer L, Ballantine T, Martuza RL, Tynes S, Giriunas I, et al: Cingulotomy for refractory obsessivecompulsive disorder. A long-term follow-up of 33 patients. Arch Gen Psychiatry 48:548-555, 1991

69. Jessup RK, Busemeyer JR, Brown JW: Error effects in anterior cingulate cortex reverse when error likelihood is high. $\mathbf{J}$ Neurosci 30:3467-3472, 2010

70. Jimenez F, Nicolini H, Lozano AM, Piedimonte F, Salin $\mathrm{R}$, Velasco F: Electrical stimulation of the inferior thalamic peduncle in the treatment of major depression and obsessive compulsive disorders. World Neurosurg 80:S30.e17-S30. $\mathrm{e} 25,2013$

71. Julien D, O'Connor KP, Aardema F: Intrusive thoughts, obsessions, and appraisals in obsessive-compulsive disorder: a critical review. Clin Psychol Rev 27:366-383, 2007

72. Jung HH, Chang WS, Rachmilevitch I, Tlusty T, Zadicario E, Chang JW: Different magnetic resonance imaging patterns after transcranial magnetic resonance-guided focused ultrasound of the ventral intermediate nucleus of the thalamus and anterior limb of the internal capsule in patients with essential tremor or obsessive-compulsive disorder. J Neurosurg 122:162-168, 2015
73. Jung HH, Kim CH, Chang JH, Park YG, Chung SS, Chang JW: Bilateral anterior cingulotomy for refractory obsessive-compulsive disorder: Long-term follow-up results . Stereotact Funct Neurosurg 84:184-189, 2006

74. Kaczkurkin AN, Lissek S: Generalization of conditioned fear and obsessive-compulsive traits. J Psychol Psychother 7:3, 2013

75. Kahneman D: Thinking, Fast and Slow. New York: Farrar, Straus and Giroux, 2011

76. Kang DH, Jang JH, Han JY, Kim JH, Jung WH, Choi JS, et al: Neural correlates of altered response inhibition and dysfunctional connectivity at rest in obsessive-compulsive disorder. Prog Neuropsychopharmacol Biol Psychiatry 40:340-346, 2013

77. Kang DH, Kim JJ, Choi JS, Kim YI, Kim CW, Youn T, et al: Volumetric investigation of the frontal-subcortical circuitry in patients with obsessive-compulsive disorder. $\mathbf{J}$ Neuropsychiatry Clin Neurosci 16:342-349, 2004

78. Karadağ F, Kalkan Oğuzhanoğlu N, Yüksel D, Kıraç S, Cura C, Ozdel O, et al: The comparison of pre- and posttreatment ${ }^{99 \mathrm{~m} T c}$ HMPAO brain SPECT images in patients with obsessive-compulsive disorder. Psychiatry Res 213:169-177, 2013

79. Kennedy SH, Giacobbe P, Rizvi SJ, Placenza FM, Nishikawa Y, Mayberg HS, et al: Deep brain stimulation for treatment-resistant depression: follow-up after 3 to 6 years. Am J Psychiatry 168:502-510, 2011

80. Kim JP, Chang WS, Park YS, Chang JW: Impact of ventralis caudalis deep brain stimulation combined with stereotactic bilateral cingulotomy for treatment of post-stroke pain. Stereotact Funct Neurosurg 90:9-15, 2012

81. Knutson B, Taylor J, Kaufman M, Peterson R, Glover G: Distributed neural representation of expected value. J Neurosci 25:4806-4812, 2005

82. Kopřivová J, Congedo M, Horáček J, Praško J, Raszka M, Brunovský M, et al: EEG source analysis in obsessive-compulsive disorder. Clin Neurophysiol 122:1735-1743, 2011

83. Kühn S, Kaufmann C, Simon D, Endrass T, Gallinat J, Kathmann N: Reduced thickness of anterior cingulate cortex in obsessive-compulsive disorder. Cortex 49:2178-2185, 2013

84. Lacerda ALT, Dalgalarrondo P, Caetano D, Camargo EE, Etchebehere ECSC, Soares JC: Elevated thalamic and prefrontal regional cerebral blood flow in obsessive-compulsive disorder: a SPECT study. Psychiatry Res 123:125-134, 2003

85. Le Jeune F, Vérin M, N'Diaye K, Drapier D, Leray E, Du Montcel ST, et al: Decrease of prefrontal metabolism after subthalamic stimulation in obsessive-compulsive disorder: a positron emission tomography study. Biol Psychiatry 68: $1016-1022,2010$

86. Levine JB, Gruber SA, Baird AA, Yurgelun-Todd D: Obsessive-compulsive disorder among schizophrenic patients: an exploratory study using functional magnetic resonance imaging data. Compr Psychiatry 39:308-311, 1998

87. Li P, Li S, Dong Z, Luo J, Han H, Xiong H, et al: Altered resting state functional connectivity patterns of the anterior prefrontal cortex in obsessive-compulsive disorder. Neuroreport 23:681-686, 2012

88. Liu K, Zhang H, Liu C, Guan Y, Lang L, Cheng Y, et al: Stereotactic treatment of refractory obsessive compulsive disorder by bilateral capsulotomy with 3 years follow-up. J Clin Neurosci 15:622-629, 2008

89. Liu Y, Gehring WJ, Weissman DH, Taylor SF, Fitzgerald KD: Trial-by-trial adjustments of cognitive control following errors and response conflict are altered in pediatric obsessive compulsive disorder. Front Psychiatry 3:41, 2012 
90. Lochner C, Fouché JP, du Plessis S, Spottiswoode B, Seedat $\mathrm{S}$, Fineberg N, et al: Evidence for fractional anisotropy and mean diffusivity white matter abnormalities in the internal capsule and cingulum in patients with obsessive-compulsive disorder. J Psychiatry Neurosci 37:193-199, 2012

91. Lopes AC, Greenberg BD, Canteras MM, Batistuzzo MC, Hoexter MQ, Gentil AF, et al: Gamma ventral capsulotomy for obsessive-compulsive disorder: a randomized clinical trial. JAMA Psychiatry 71:1066-1076, 2014

92. Lozano AM, Giacobbe P, Hamani C, Rizvi SJ, Kennedy SH, Kolivakis TT, et al: A multicenter pilot study of subcallosal cingulate area deep brain stimulation for treatmentresistant depression. J Neurosurg 116:315-322, 2012

93. Luyten L, Hendrickx S, Raymaekers S, Gabriëls L, Nuttin $\mathrm{B}$ : Electrical stimulation in the bed nucleus of the stria terminalis alleviates severe obsessive-compulsive disorder. Mol Psychiatry [epub ahead of print], 2015

94. Machlin SR, Harris GJ, Pearlson GD, Hoehn-Saric R, Jeffery P, Camargo EE: Elevated medial-frontal cerebral blood flow in obsessive-compulsive patients: a SPECT study. Am J Psychiatry 148: 1240-1242, 1991

95. Mallet L, Polosan M, Jaafari N, Baup N, Welter ML, Fontaine D, et al: Subthalamic nucleus stimulation in severe obsessive-compulsive disorder. N Engl J Med 359:21212134, 2008

96. Mallet N, Le Moine C, Charpier S, Gonon F: Feedforward inhibition of projection neurons by fast-spiking GABA interneurons in the rat striatum in vivo. J Neurosci 25:3857-3869, 2005

97. Malone DA Jr, Dougherty DD, Rezai AR, Carpenter LL, Friehs GM, Eskandar EN, et al: Deep brain stimulation of the ventral capsule/ventral striatum for treatment-resistant depression. Biol Psychiatry 65:267-275, 2009

98. Maltby N, Tolin DF, Worhunsky P, O’Keefe TM, Kiehl KA: Dysfunctional action monitoring hyperactivates frontalstriatal circuits in obsessive-compulsive disorder: an eventrelated fMRI study. Neuroimage 24:495-503, 2005

99. Marsh R, Horga G, Parashar N, Wang Z, Peterson BS, Simpson HB: Altered activation in fronto-striatal circuits during sequential processing of conflict in unmedicated adults with obsessive-compulsive disorder. Biol Psychiatry 75:615-622, 2014

100. Matsumoto R, Ito H, Takahashi H, Ando T, Fujimura Y, Nakayama K, et al: Reduced gray matter volume of dorsal cingulate cortex in patients with obsessive-compulsive disorder: a voxel-based morphometric study. Psychiatry Clin Neurosci 64:541-547, 2010

101. McGuire JT, Botvinick MM: Prefrontal cortex, cognitive control, and the registration of decision costs. Proc Natl Acad Sci U S A 107:7922-7926, 2010

102. McGuire PK, Bench CJ, Frith CD, Marks IM, Frackowiak RS, Dolan RJ: Functional anatomy of obsessive-compulsive phenomena. Br J Psychiatry 164:459-468, 1994

103. Mian MK, Campos M, Sheth SA, Eskandar EN: Deep brain stimulation for obsessive-compulsive disorder: past, present, and future. Neurosurg Focus 29(2):E10, 2010

104. Milad MR, Furtak SC, Greenberg JL, Keshaviah A, Im JJ, Falkenstein MJ, et al: Deficits in conditioned fear extinction in obsessive-compulsive disorder and neurobiological changes in the fear circuit. JAMA Psychiatry 70:608-618, 554, 2013

105. Milad MR, Quirk GJ, Pitman RK, Orr SP, Fischl B, Rauch SL: A role for the human dorsal anterior cingulate cortex in fear expression. Biol Psychiatry 62:1191-1194, 2007

106. Milad MR, Rauch SL: Obsessive-compulsive disorder: beyond segregated cortico-striatal pathways. Trends Cogn Sci 16:43-51, 2012 (Regul Ed)

107. Mitra PP, Bokil H: Observed Brain Dynamics. New York: Oxford University Press, 2008
108. Moher D, Shamseer L, Clarke M, Ghersi D, Liberati A, Petticrew M, et al: Preferred reporting items for systematic review and meta-analysis protocols (PRISMA-P) 2015 statement. Syst Rev 4:1, 2015

109. Morecraft RJ, McNeal DW, Stilwell-Morecraft KS, Gedney M, Ge J, Schroeder CM, et al: Amygdala interconnections with the cingulate motor cortex in the rhesus monkey. $\mathbf{J}$ Comp Neurol 500:134-165, 2007

110. Morecraft RJ, Stilwell-Morecraft KS, Rossing WR: The motor cortex and facial expression: new insights from neuroscience. Neurologist 10:235-249, 2004

111. Morgiève M, N'Diaye K, Haynes WIA, Granger B, Clair AH, Pelissolo A, et al: Dynamics of psychotherapy-related cerebral haemodynamic changes in obsessive compulsive disorder using a personalized exposure task in functional magnetic resonance imaging. Psychol Med 44:1461-1473, 2014

112. Murayama K, Nakao T, Sanematsu H, Okada K, Yoshiura T, Tomita M, et al: Differential neural network of checking versus washing symptoms in obsessive-compulsive disorder. Prog Neuropsychopharmacol Biol Psychiatry 40:160-166, 2013

113. Myers SG, Fisher PL, Wells A: Belief domains of the Obsessive Beliefs Questionnaire-44 (OBQ-44) and their specific relationship with obsessive-compulsive symptoms. J Anxiety Disord 22:475-484, 2008

114. Nabeyama M, Nakagawa A, Yoshiura T, Nakao T, Nakatani E, Togao O, et al: Functional MRI study of brain activation alterations in patients with obsessive-compulsive disorder after symptom improvement. Psychiatry Res 163:236-247, 2008

115. Nakao T, Nakagawa A, Yoshiura T, Nakatani E, Nabeyama M, Yoshizato C, et al: A functional MRI comparison of patients with obsessive-compulsive disorder and normal controls during a Chinese character Stroop task. Psychiatry Res 139:101-114, 2005

116. Nanbu M, Kurayama T, Nakazawa K, Matsuzawa D, Komiya Z, Haraguchi T, et al: Impaired P50 suppression in fear extinction in obsessive-compulsive disorder. Prog Neuropsychopharmacol Biol Psychiatry 34:317-322, 2010

117. Oliver B, Gascón J, Aparicio A, Ayats E, Rodriguez R, Maestro De León JL, et al: Bilateral anterior capsulotomy for refractory obsessive-compulsive disorders. Stereotact Funct Neurosurg 81:90-95, 2003

118. Papageorgiou CC, Rabavilas AD: Abnormal P600 in obsessive-compulsive disorder. A comparison with healthy controls. Psychiatry Res 119:133-143, 2003

119. Patel SR, Aronson JP, Sheth SA, Eskandar EN: Lesion procedures in psychiatric neurosurgery. World Neurosurg 80:S31.e9-S31.e16, 2013

120. Pauls DL, Abramovitch A, Rauch SL, Geller DA: Obsessive-compulsive disorder: an integrative genetic and neurobiological perspective. Nat Rev Neurosci 15:410424, 2014

121. Paus T: Primate anterior cingulate cortex: where motor control, drive and cognition interface. Nat Rev Neurosci 2:417-424, 2001

122. Paus T, Tomaiuolo F, Otaky N, MacDonald D, Petrides M, Atlas J, et al: Human cingulate and paracingulate sulci: pattern, variability, asymmetry, and probabilistic map. Cereb Cortex 6:207-214, 1996

123. Perani D, Colombo C, Bressi S, Bonfanti A, Grassi F, Scarone S, et al: $\left[{ }^{18} \mathrm{~F}\right]$ FDG PET study in obsessive-compulsive disorder. A clinical/metabolic correlation study after treatment. Br J Psychiatry 166:244-250, 1995

124. Perani D, Garibotto V, Gorini A, Moresco RM, Henin M, Panzacchi A, et al: In vivo PET study of $5 \mathrm{HT}_{2 \mathrm{~A}}$ serotonin and $\mathrm{D}_{2}$ dopamine dysfunction in drug-naive obsessive-compulsive disorder. Neuroimage 42:306-314, 2008 
125. Pereira EAC, Paranathala M, Hyam JA, Green AL, Aziz TZ: Anterior cingulotomy improves malignant mesothelioma pain and dyspnoea. Br J Neurosurg 28:471-474, 2014

126. Posner J, Marsh R, Maia TV, Peterson BS, Gruber A, Simpson HB: Reduced functional connectivity within the limbic cortico-striato-thalamo-cortical loop in unmedicated adults with obsessive-compulsive disorder. Hum Brain Mapp 35:2852-2860, 2014

127. Rauch SL, Dougherty DD, Cosgrove GR, Cassem EH, Alpert NM, Price BH, et al: Cerebral metabolic correlates as potential predictors of response to anterior cingulotomy for obsessive compulsive disorder. Biol Psychiatry 50:659667,2001

128. Rauch SL, Dougherty DD, Malone D, Rezai A, Friehs G, Fischman AJ, et al: A functional neuroimaging investigation of deep brain stimulation in patients with obsessive-compulsive disorder. J Neurosurg 104:558-565, 2006

129. Rauch SL, Savage CR, Alpert NM, Dougherty D, Kendrick A, Curran T, et al: Probing striatal function in obsessivecompulsive disorder: a PET study of implicit sequence learning. J Neuropsychiatry Clin Neurosci 9:568-573, 1997

130. Rauch SL, Shin LM, Dougherty DD, Alpert NM, Fischman AJ, Jenike MA: Predictors of fluvoxamine response in contamination-related obsessive compulsive disorder: a PET symptom provocation study. Neuropsychopharmacology 27:782-791, 2002

131. Reed GF: The obsessional-compulsive experience: A phenomenological re-emphasis. Philos Phenomenol Res 37:381-384, 1977

132. Remijnse PL, van den Heuvel OA, Nielen MMA, Vriend C, Hendriks GJ, Hoogendijk WJG, et al: Cognitive inflexibility in obsessive-compulsive disorder and major depression is associated with distinct neural correlates. PLoS One 8:e59600, 2013

133. Riffkin J, Yücel M, Maruff P, Wood SJ, Soulsby B, Olver J, et al: A manual and automated MRI study of anterior cingulate and orbito-frontal cortices, and caudate nucleus in obsessive-compulsive disorder: comparison with healthy controls and patients with schizophrenia. Psychiatry Res 138:99-113, 2005

134. Rosenberg DR, Averbach DH, O'Hearn KM, Seymour AB, Birmaher B, Sweeney JA: Oculomotor response inhibition abnormalities in pediatric obsessive-compulsive disorder. Arch Gen Psychiatry 54:831-838, 1997

135. Rotge JY, Dilharreguy B, Aouizerate B, Martin-Guehl C, Guehl D, Jaafari N, et al: Inverse relationship between thalamic and orbitofrontal volumes in obsessive-compulsive disorder. Prog Neuropsychopharmacol Biol Psychiatry 33:682-687, 2009

136. Roth RM, Saykin AJ, Flashman LA, Pixley HS, West JD, Mamourian AC: Event-related functional magnetic resonance imaging of response inhibition in obsessive-compulsive disorder. Biol Psychiatry 62:901-909, 2007

137. Rück C, Karlsson A, Steele JD, Edman G, Meyerson BA, Ericson K, et al: Capsulotomy for obsessive-compulsive disorder: long-term follow-up of 25 patients. Arch Gen Psychiatry 65:914-921, 2008

138. Ruscio AM, Stein DJ, Chiu WT, Kessler RC: The epidemiology of obsessive-compulsive disorder in the National Comorbidity Survey Replication. Mol Psychiatry 15:5363,2010

139. Rushworth MF, Noonan MP, Boorman ED, Walton ME, Behrens TE: Frontal cortex and reward-guided learning and decision-making. Neuron 70:1054-1069, 2011

140. Sachdev PS, Malhi GS: Obsessive-compulsive behaviour: a disorder of decision-making. Aust N Z J Psychiatry 39:757-763, 2005

141. Saxena S, Rauch SL: Functional neuroimaging and the neuroanatomy of obsessive-compulsive disorder. Psychiatr Clin North Am 23:563-586, 2000

142. Schiepek G, Tominschek I, Karch S, Lutz J, Mulert C, Meindl T, et al: A controlled single case study with repeated fMRI measurements during the treatment of a patient with obsessive-compulsive disorder: testing the nonlinear dynamics approach to psychotherapy. World J Biol Psychiatry 10:658-668, 2009

143. Schlösser RGM, Wagner G, Schachtzabel C, Peikert G, Koch K, Reichenbach JR, et al: Fronto-cingulate effective connectivity in obsessive compulsive disorder: a study with fMRI and dynamic causal modeling. Hum Brain Mapp 31:1834-1850, 2010

144. Shackman AJ, Salomons TV, Slagter HA, Fox AS, Winter JJ, Davidson RJ: The integration of negative affect, pain and cognitive control in the cingulate cortex. Nat Rev Neurosci 12:154-167, 2011

145. Shenhav A, Botvinick MM, Cohen JD: The expected value of control: an integrative theory of anterior cingulate cortex function. Neuron 79:217-240, 2013

146. Sheth SA, Mian MK, Patel SR, Asaad WF, Williams ZM, Dougherty DD, et al: Human dorsal anterior cingulate cortex neurons mediate ongoing behavioural adaptation. Nature 488:218-221, 2012

147. Sheth SA, Neal J, Tangherlini F, Mian MK, Gentil A, Cosgrove GR, et al: Limbic system surgery for treatmentrefractory obsessive-compulsive disorder: a prospective long-term follow-up of 64 patients. J Neurosurg 118:491497, 2013

148. Shields DC, Asaad W, Eskandar EN, Jain FA, Cosgrove GR, Flaherty AW, et al: Prospective assessment of stereotactic ablative surgery for intractable major depression. Biol Psychiatry 64:449-454, 2008

149. Shim G, Jung WH, Choi JS, Jung MH, Jang JH, Park JY, et al: Reduced cortical folding of the anterior cingulate cortex in obsessive-compulsive disorder. J Psychiatry Neurosci 34:443-449, 2009

150. Skoog G, Skoog I: A 40-year follow-up of patients with obsessive-compulsive disorder. Arch Gen Psychiatry 56:121-127, 1999

151. Stern ER, Fitzgerald KD, Welsh RC, Abelson JL, Taylor SF: Resting-state functional connectivity between frontoparietal and default mode networks in obsessive-compulsive disorder. PLoS One 7:e36356, 2012

152. Swedo SE, Schapiro MB, Grady CL, Cheslow DL, Leonard HL, Kumar A, et al: Cerebral glucose metabolism in childhood-onset obsessive-compulsive disorder. Arch Gen Psychiatry 46:518-523, 1989

153. Szeszko PR, Ardekani BA, Ashtari M, Malhotra AK, Robinson DG, Bilder RM, et al: White matter abnormalities in obsessive-compulsive disorder: a diffusion tensor imaging study. Arch Gen Psychiatry 62:782-790, 2005

154. Taylor S: Etiology of obsessions and compulsions: a metaanalysis and narrative review of twin studies. Clin Psychol Rev 31:1361-1372, 2011

155. Togao O, Yoshiura T, Nakao T, Nabeyama M, Sanematsu $\mathrm{H}$, Nakagawa A, et al: Regional gray and white matter volume abnormalities in obsessive-compulsive disorder: a voxel-based morphometry study. Psychiatry Res 184:29-37, 2010

156. Tolin DF, Witt ST, Stevens MC: Hoarding disorder and obsessive-compulsive disorder show different patterns of neural activity during response inhibition. Psychiatry Res 221:142-148, 2014

157. Valente AA Jr, Miguel EC, Castro CC, Amaro E Jr, Duran FLS, Buchpiguel CA, et al: Regional gray matter abnormalities in obsessive-compulsive disorder: a voxel-based morphometry study. Biol Psychiatry 58:479-487, 2005

158. van den Heuvel OA, Veltman DJ, Groenewegen HJ, Witter 
MP, Merkelbach J, Cath DC, et al: Disorder-specific neuroanatomical correlates of attentional bias in obsessive-compulsive disorder, panic disorder, and hypochondriasis. Arch Gen Psychiatry 62:922-933, 2005

159. van den Heuvel OA, van der Werf YD, Verhoef KM, de Wit S, Berendse HW, Wolters EC, et al: Frontal-striatal abnormalities underlying behaviours in the compulsiveimpulsive spectrum. J Neurol Sci 289:55-59, 2010

160. van Westen M, Rietveld E, Figee M, Denys D: Clinical outcome and mechanisms of deep brain stimulation for obsessive-compulsive disorder. Curr Behav Neurosci Rep 2:41-48, 2015

161. Veale DM, Sahakian BJ, Owen AM, Marks IM: Specific cognitive deficits in tests sensitive to frontal lobe dysfunction in obsessive-compulsive disorder. Psychol Med 26: $1261-1269,1996$

162. Venkatasubramanian G, Zutshi A, Jindal S, Srikanth SG, Kovoor JME, Kumar JK, et al: Comprehensive evaluation of cortical structure abnormalities in drug-naïve, adult patients with obsessive-compulsive disorder: a surfacebased morphometry study. J Psychiatr Res 46:1161-1168, 2012

163. Viswanathan A, Harsh V, Pereira EAC, Aziz TZ: Cingulotomy for medically refractory cancer pain. Neurosurg Focus 35(3):E1, 2013

164. Vriend C, de Wit SJ, Remijnse PL, van Balkom AJLM, Veltman DJ, van den Heuvel OA: Switch the itch: A naturalistic follow-up study on the neural correlates of cognitive flexibility in obsessive-compulsive disorder. Psychiatry Res Neuroimaging 213:31-38, 2013

165. Wang C, Ulbert I, Schomer DL, Marinkovic K, Halgren E: Responses of human anterior cingulate cortex microdomains to error detection, conflict monitoring, stimulus-response mapping, familiarity, and orienting. J Neurosci 25:604 613,2005

166. Whitty CW, Duffield JE, Tov' PM, Cairns H: Anterior cingulectomy in the treatment of mental disease. Lancet 1:475-481, 1952

167. Williams SM, Goldman-Rakic PS: Widespread origin of the primate mesofrontal dopamine system. Cereb Cortex 8:321-345, 1998

168. Womelsdorf T, Johnston K, Vinck M, Everling S: Thetaactivity in anterior cingulate cortex predicts task rules and their adjustments following errors. Proc Natl Acad Sci U S A 107:5248-5253, 2010

169. Wong ET, Gunes S, Gaughan E, Patt RB, Ginsberg LE,
Hassenbusch SJ, et al: Palliation of intractable cancer pain by MRI-guided cingulotomy. Clin J Pain 13:260-263, 1997

170. Yen CP, Kuan CY, Sheehan J, Kung SS, Wang CC, Liu $\mathrm{CK}$, et al: Impact of bilateral anterior cingulotomy on neurocognitive function in patients with intractable pain. J Clin Neurosci 16:214-219, 2009

171. Yen CP, Kung SS, Su YF, Lin WC, Howng SL, Kwan AL: Stereotactic bilateral anterior cingulotomy for intractable pain. J Clin Neurosci 12:886-890, 2005

172. Zhan S, Liu W, Li D, Pan S, Pan Y, Li Y, et al: Long-term follow-up of bilateral anterior capsulotomy in patients with refractory obsessive-compulsive disorder. Clin Neurol Neurosurg 119:91-95, 2014

173. Zhang QJ, Wang WH, Wei XP: Long-term efficacy of stereotactic bilateral anterior cingulotomy and bilateral anterior capsulotomy as a treatment for refractory obsessive-compulsive disorder. Stereotact Funct Neurosurg 91:258-261, 2013

174. Lopes AC, Greenberg BD, Pereira CAB, Norén G, Miguel EC: Notice of retraction and replacement. Lopes et al. Gamma ventral capsulotomy for obsessive-compulsive disorder: a randomized clinical trial. JAMA Psychiatry. 2014;71(9):1066-1076. JAMA Psychiatry 72:1258, 2015

\section{Disclosures}

The authors report no conflict of interest concerning the materials or methods used in this paper or the findings specified in this paper.

\section{Author Contributions}

Conception and design: both authors. Acquisition of data: McGovern. Analysis and interpretation of data: both authors. Drafting the article: both authors. Critically revising the article: both authors. Reviewed submitted version of manuscript: both authors. Approved the final version of the manuscript on behalf of both authors: Sheth. Administrative/technical/material support: Sheth. Study supervision: Sheth.

\section{Correspondence}

Sameer A. Sheth, Department of Neurological Surgery, The Neurological Institute, Columbia University Medical Center, $710 \mathrm{~W}$ 168th St., New York, NY 10032. email: ss4451@cumc.columbia. edu. 